\title{
ACR
}

Selected Papers of \#AoIR2019: The $20^{\text {th }}$ Annual Conference of the Association of Internet Researchers Brisbane, Australia / 2-5 October 2019

\section{A NEW STANDARD OF PROOF? DISCOURSES ON VISUAL DATA AFTER THE 2017 G20-PROTESTS}

\author{
Rebecca Venema \\ Università della Svizzera italiana \\ Katharina Lobinger \\ Università della Svizzera italiana
}

\begin{abstract}
A broad body of literature has described contemporary societies as "surveillance societies" or "surveillance cultures" (Lyon, 2007, 2017) and has expanded on the implications of an increasing "datafication" of society (Hintz, Dencik \& Wahl-Jorgensen, 2019) and dataveillance (van Dijck, 2014). These concepts attend to a profound transformation in state-corporate-citizen-relationships and in how society is ordered, decisions are made and citizens are monitored through data.

So far, the role of visual data and visual analysis in these processes has seldom been discussed in detail. However, visual data, the combination of visual representations of e.g. persons, their physical and facial traits with metadata, and advancing algorithmic and facial recognition tools for their analysis are ubiquitous and can provide particularly rich insights. This also makes them a paramount example for key tensions in datafied societies between security and surveillance on the one, and data protection and privacy on the other hand.
\end{abstract}

Both, potentials and possible problems of ubiquitous visual technologies, extensive amounts of images and videos taken and shared and facial recognition tools seem myriad. One the one hand, they may be valuable for identifying terrorists or finding a missing child and can thus open up new opportunities for public security policies and law enforcement. On the other hand, these new avenues can also be considered a significant threat to data protection and fundamental human rights like privacy. Not at least, problems of accuracy and biases have been found in the performance of face recognition technologies (Boulamwini, 2018), which raise the significant question of how much to trust algorithms and the classifications they perform. Overall, this calls for further insights into 1) the intersections of datafication, dataveillance, and visual communication and 2) how different authorities and stakeholders legitimate and contest the collection of visual data and their algorithmic analysis in the political and public realm.

Suggested Citation (APA): Venema, R., \& Lobinger, K. (2019, October 2-5). A New Standard of Proof? Discourses on Visual Data After the 2017 G20-Protests. Paper presented at AoIR 2019: The 20th Annual Conference of the Association of Internet Researchers. Brisbane, Australia: AolR. Retrieved from http://spir.aoir.org. 
The police investigations after various violent confrontations between police forces and protesters, riots, and lootings during the G20-summit 2017 in Hamburg are an intriguing and rich case study for this purpose. First, law enforcement is considered a key site for understanding the politics of the datafied society (Hintz et al. 2019). Second, visual data and algorithmic analytical tools played a pivotal role in this case. Hamburg's police collected more than 100 TB of visual data that was analyzed with the help of Videmo, a third-party face detection and face recognition tool. Moreover, the police launched a European-wide public search for which more than 100 pictures of suspects were published online. What is particular for the G20-prosecutions is that they triggered diverse controversial public and political debates. This allows gaining insights into practices of visual data collection and analysis and into how they were discussed in news media coverage, in ad hoc and hashtag publics and among different state authorities and political decisionmakers.

Drawing on a qualitative content and discourse analysis, the present study first compiles information about how visual data was produced and collected, stored and analyzed. Second, it traces how these practices were legitimated and contested.

Materials for the analysis are (a) two expert's reports by the commissioner for data protection in the city of Hamburg (b) minutes of fifteen committee hearings and three parliamentary debates, (c) six official police press communiqués. Moreover, we analyzed (d) 95 articles published in regional and high-circulation national print and online news media and on a blog and news website. For the heated debate on the public search, we additionally (e) collected and analyzed tweets $(n=267)$ with the hashtag-combination \#G20 / \#NoG20 and \#Öffentlichkeitsfahndung (public search).

Findings show that photographs and videos used in the investigation process were taken for different initial purposes. State and corporate-produced visual data stemming from CCTV cameras in public transportation services and stations were complemented with photographs and videos taken by journalists and by private individuals. Hamburg's police had asked the public to upload images on a dedicated platform, which also allowed for anonymous uploads. In total, the visual data covered large parts of public life in the inner city of Hamburg during the summit days. During the analysis, digital faceprints of all identifiable persons in the dataset were stored.

The general media coverage was mostly concerned with the public search and the publication of suspects' pictures online. Even though visual data and algorithmic analytical tools played a pivotal role in the prosecution process, the concrete practices by which visual data were collected and analyzed remained rather invisible or obscure in the general media coverage. In the expert's reports, parliamentary debates, leftist local and online news media, in turn, they were discussed extensively. Trust thereby emerges as a multilayered key issue. First, we see strong affirmations of trust in technologies, algorithms, and the information and evidence they are able to provide. Hamburg's criminal investigation department praised the wealth of visual data and specifically the algorithmic and facial recognition software tools as an immense forensic advantage, "uncharted technological territory" and "a new standard of proof". Visual data and the algorithmic tools are thus characterized and legitimized as powerful, objective and specifically trustworthy tools. Second, we see that practices of visual data 
collection and analysis triggered fundamental concerns about the role and the trustworthiness of police authorities in datafied societies. Hamburg's data commissioner and various liberal politicians expressed fundamental concerns regarding the ethical, social and legal implications of the concrete data collection and the analyses. They criticized the indiscriminate collection, storage and analysis of digital faceprints of thousands of people and characterized it as an infringement to informational selfdetermination and privacy by police authorities. Consequently, they urged for a comprehensive legal regulatory framework to prevent police authorities to take significant steps towards a surveillance and police state.

Taken together, the findings prompt fundamental challenges for society and tasks for critical research. The possibility to visually cover and track public life in large parts of a city and the highly critical attitudes towards police authorities underline the necessity to 'bring the visual' into debates on datafication, dataveillance, and surveillance, their implications for social life and a broader discussion on how we want to live in a datafied society. Moreover, the strong affirmation of trust in visual data and facial recognition tools expressed by Hamburg's criminal investigation department is a call for further studies on tools, their logics and the (political) contexts in which they are developed to be able to understand and critically assess the analytical steps applied. This input is urgently needed as the use of algorithmic tools was a pivotal and far-reaching step in the G20-investigations but remained a blind spot in the general media coverage.

\section{References}

Boulamwini, J. (2018). Limited vision: The undersampled majority. Fullpaper presented at the Annual Conference of the International Communication Association (ICA), May 24-28, Prague.

Hintz, A., Dencik, L., \& Wahl-Jorgensen, K. (2019). Digital citizenship in a datafied society. Cambridge: Polity Press.

Lyon, D. (2017). Surveillance culture: Engagement, exposure, and ethics in digital modernity. International Journal of Communication, 11, 824-842.

https://ijoc.org/index.php/ijoc/article/view/5527/1933

Lyon, D. (2007). Surveillance studies: An overview. Cambridge: Polity Press.

van Dijck, J. (2014). Datafication, dataism and dataveillance: Big data between scientific paradigm and ideology. Surveillance \& Society, 12(2), 197-208.

https://doi.org/10.24908/ss.v12i2.4776 